\title{
Academic politics?
}

\section{Kirk Dombrowski}

Published online: 5 May 2009

(c) Springer Science+Business Media B.V. 2009

Photo by Kirk Dombrowski. 365 5th Avenue, New York City.

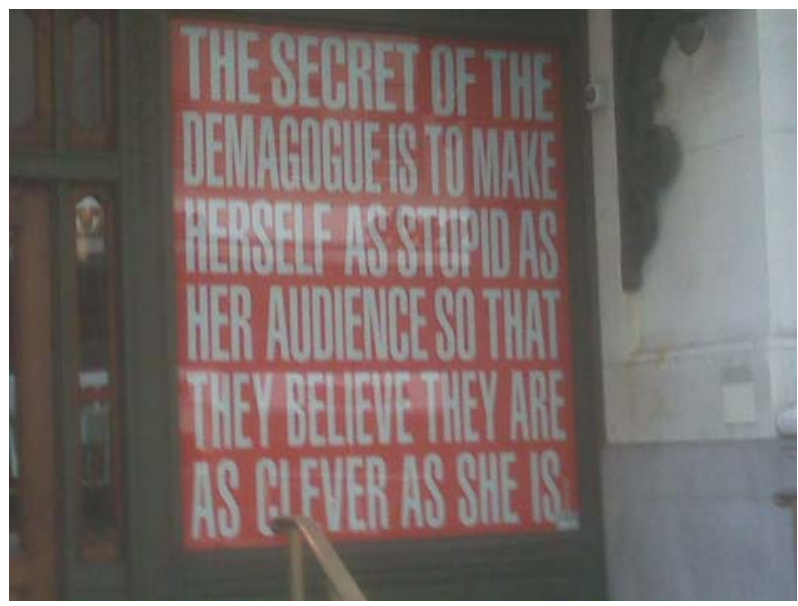

K. Dombrowski $(\bowtie)$

CUNY Graduate Center and John Jay College, The City University of New York,

New York, NY, USA

e-mail: kdombrowski@jjay.cuny.edu 